\title{
ANÁLISIS SIG PARA EL DISEÑO DE UN PRODUCTO TURÍSTICO: LA LOCALIZACIÓN DEL MUNICIPIO Y DEL PUEBLO A MAYOR ALTITUD DE ESPAÑA
}

\author{
Enrique Montón Chiva \\ José Quereda Sala \\ Victoria Quereda Vázquez. \\ Universitat Jaume I. Castellón de la Plana
}

\section{RESUMEN}

Existe un turismo geográfico, que busca visitar puntos destacados en el relieve, ríos o fronteras. Sin embargo, algunos de esos puntos muy renombrados no escapan al error. Dos localidades se han disputado el título de ser la más elevada de España. El presente estudio hace uso de los Sistemas de Información Geográfica para resolver esta cuestión. Aplicación que ha permitido demostrar que Valdelinares (Teruel) es el pueblo de mayor altitud de España y Trevélez (Granada), el municipio, justo al contrario de lo que hacen gala las placas situadas a la entrada de sus respectivos núcleos urbanos.

Palabras clave: Sistema de Información Geográfica, Modelo Digital del Terreno, turismo, pueblo, municipio, altitud.

\section{GIS analysis for the design of a touristic product: locating of the highest village and municipality of Spain}

\section{ABSTRACT}

There is a form of geographic tourism, intended to visit main points in the relief, rivers or borders. Nevertheless, some of these very famous places are not immune to error. Two settlements have disputed the award of being the highest in Spain. This study makes use

Recibido: 9 de septiembre de 2015

Devuelto para su revisión: 5 de febrero de 2016

Aceptado: 17 de marzo de 2016

Área de Análisis Geográfico Regional. Departamento de Historia, Geografía y Arte. Universitat Jaume I. Av. Sos Baynat, s/n.12071 CASTELLÓN DE LA PLANA(España).E-mail: montone@uji.es / quereda@uji.es / mquereda@uji.es 
of Geographic Information Systems to solve this issue. Furthermore, this research aims to demonstrate that Valdelinares (Teruel) is the highest village in Spain and Trevélez (Granada), the highest municipality, just the opposite of what they show at the entrance to their respective urban centres.

Keywords: Geographic Information System, Digital Terrain Model, tourism, village, municipality, altitude.

\section{ESTADO DE LA CUESTIÓN. EL TURISMO GEOGRÁFICO}

Aunque no tipificado en los manuales, existe una modalidad de turismo geográfico, que incluye algunos destinos de gran solera. Se visitan, entre otros, los lugares de mayor altitud de una región o del planeta entero; los nacimientos y desembocaduras de los ríos, confluencias destacadas, no sólo fluviales sino fronterizas; los extremos latitudinales y longitudinales de países y continentes, paralelos y meridianos señalados.

Tal vez el Everest sea el más destacado, a pesar de sus duras condiciones, lo que le ha convertido en un símbolo de la masificación turística y de la necesidad de respetar la capacidad de carga. Del mismo modo que nuestro Teide. Desde que se construyó el teleférico, entre 1963 y 1971, su ascenso es la actividad más llamativa para los más de 3,2 millones de visitantes del parque nacional homónimo (MAGRAMA, 2014:85). Para proteger su entorno, el ascenso por el sendero Telesforo Bravo, desde la Rambleta a 3.555 metros hasta los $3.717,98$ del Pico exige un permiso gratuito, expedido por las autoridades. Otros lugares bien conocidos, a diferentes escalas, son Cabo Norte, la triple confluencia de Brasil, Paraguay y Argentina o la cuádruple de Utah, Colorado, Nuevo Méjico y Arizona; el Cabo de Buena Esperanza, Finisterre; el nacimiento del Ebro o del Tajo; el punto más meridional de los Estados Unidos continentales; el ecuador que permite poner un pie en cada hemisferio, el círculo glaciar ártico, en la localidad de Rovaniemi (Finlandia), donde el singular paralelo complementa la visita a las oficinas de Papá Noel o el Observatorio de Greenwich, donde se estableció el meridiano de referencia y los turistas pagan ocho libras y hacen cola para fotografiarse con un pie en el meridiano oriental y otro, en el occidental.

Aunque algunos incluso merecen hitos conmemorativos, no han escapado a errores de bulto, convirtiéndose en atractivos turísticos sin merecerlo. Un perfecto ejemplo de cómo un buen marketing (un factor humano), vale más que las condiciones propias (un factor físico). Cabo Norte no es el punto más septentrional de la Europa continental, al encontrarse en una isla, Magerøya. La web de Turismo de Noruega especifica que es el punto accesible a pie más al norte del mundo y como Knivskjelloden, al oeste, está 1.457 metros más al norte (Visitnorway).

Una confusión semejante se produce en el Cabo de Agulhas. Este accidente geográfico queda más al sur que el cabo de Buena Esperanza, cuyo faro concentra las visitas e incluso cuenta, en su cercanía, con una tienda de nombre muy significativo: los dos océanos (figura 1). Miles de turistas visitan cada año el Monumento de las Cuatro Esquinas, donde 
confluyen Utah, Colorado, Nuevo Méjico y Arizona, aunque el punto real, establecido por el Congreso en 1863, se encuentre 550 metros al oeste, sin reconocimiento ni tiendas de recuerdos (Jennings, 2012:86).

\section{Figura 1 \\ IMAGEN DE LA TIENDA "TWO OCEANS", EN LAS CERCANÍAS DEL FARO SITO EN EL CABO DE BUENA ESPERANZA}

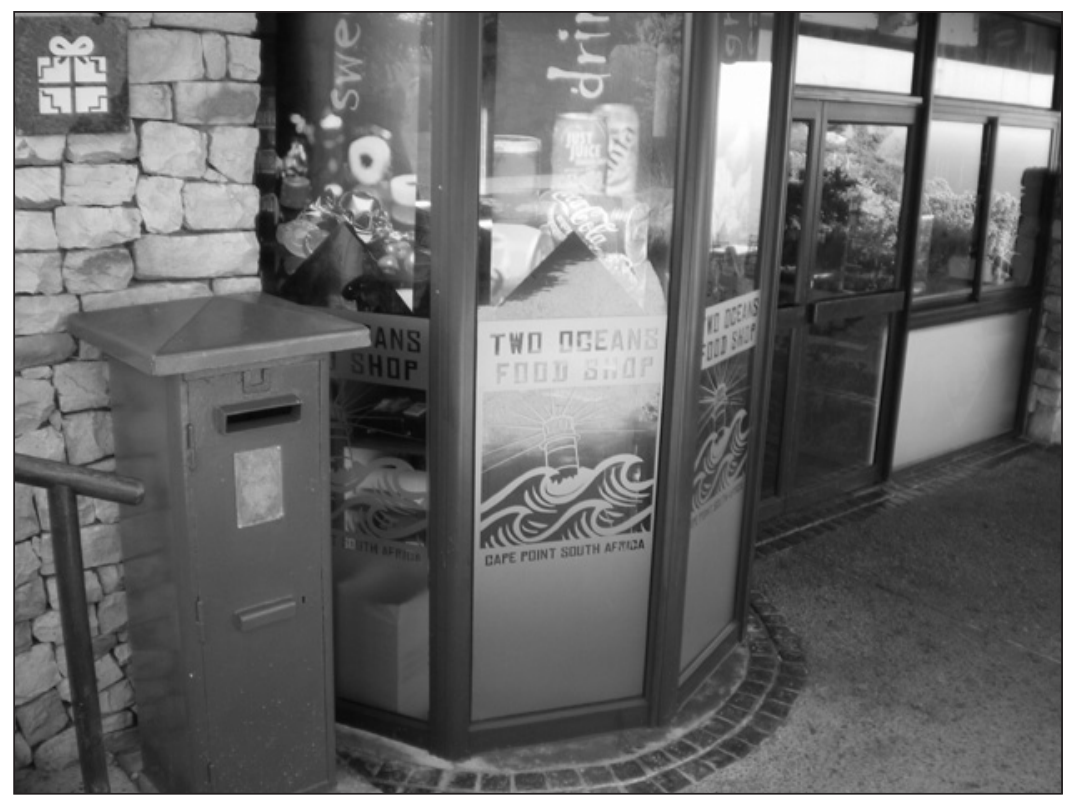

Fuente: Enrique Montón Chiva.

Los gazapos geoturísticos se extienden por todo el planeta y nuestro país no es excepción. Finisterre, "donde acaba la tierra", una extensión del archifamoso Camino de Santiago, no sólo se adentra menos en el Atlántico que una parte importante de la costa del Portugal central, culminada en el Cabo da Roca, sino que apenas unos tres kilómetros más al norte, el cabo Touriñán queda casi kilómetro y medio más al oeste, señalando el punto más occidental de la España peninsular. Sin embargo, no recibe visita alguna. Al menos está reconocida su singularidad oficialmente, pero en otros casos surgen amargas disputas no resueltas o difíciles de resolver. Como paso previo al caso que nos ocupa, podemos citar el nacimiento del Guadalquivir que guías turísticas, libros de texto y estadísticas oficiales ubican en la Cañada de las Fuentes, Sierra de Cazorla, pero que tiene otros muchos candidatos con opciones manchegas y especialmente almerienses que derivaron en una discusión tan agria de cariz político que el debate se llevó al Parlamento Andaluz (Pozo, 2011).

También disputados son los títulos de municipio o pueblo con mayor altitud de España. Trévelez (Granada) se define como el pueblo más alto de España, según reza una inscripción de cerámica en la localidad (figura 2). Por su parte, Valdelinares (Teruel) se proclama 
como el municipio más alto de España con una altitud errónea de 1.962 metros, medida en la puerta de su Iglesia (Ayuntamiento de Valdelinares). Tanto en las afueras como en el centro de la localidad, varios carteles con una altitud más acertada (1.692 metros) lo colocan como el municipio más alto de España (figura 3). El título le ha valido ser recientemente el plató del anuncio de una conocida marca de coches.

\section{Figura 2 \\ CARTEL A LA ENTRADA DE TREVÉLEZ (GRANADA) \\ POR LA CARRETERA A-4132: "BIENVENIDOS A TREVELEZ. EL PUEBLO MAS ALTO DE ESPAÑA"}

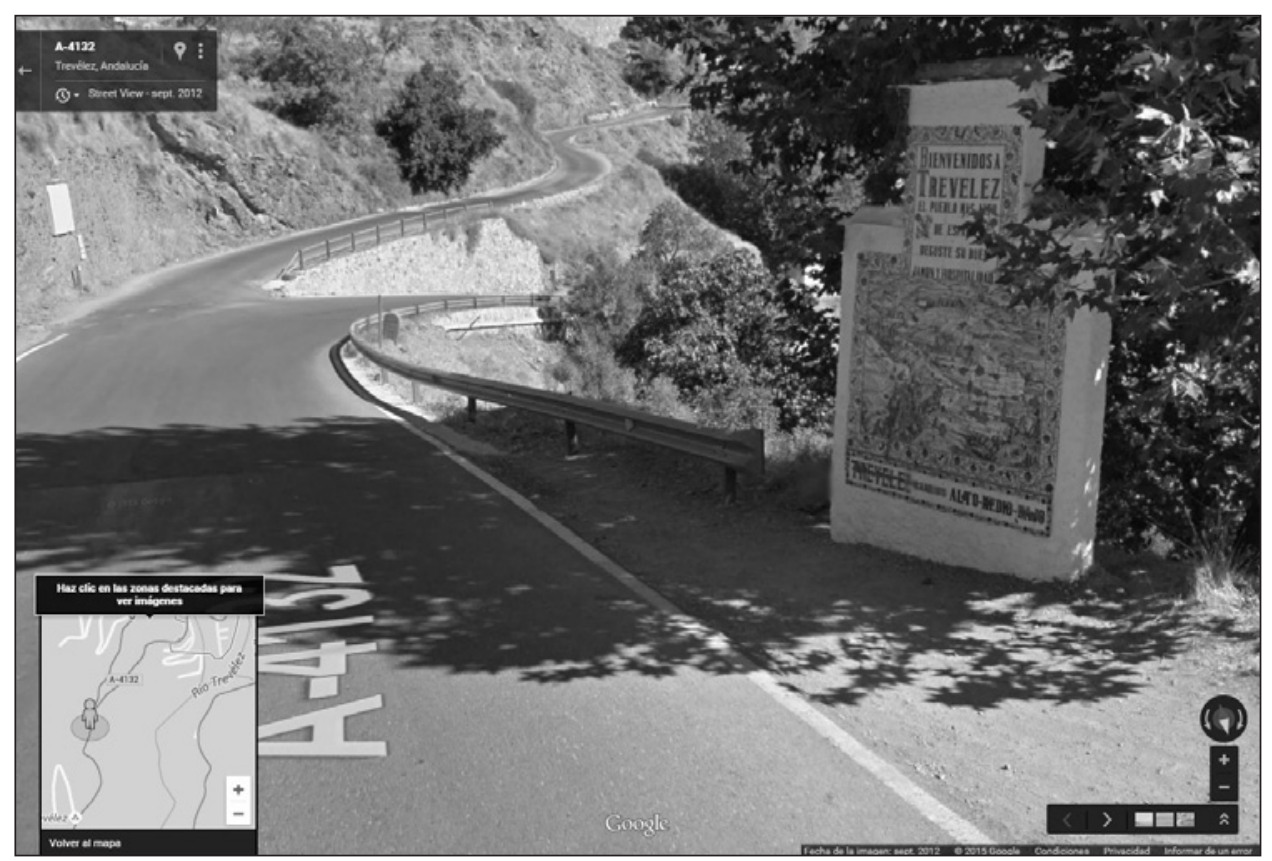

Fuente: Google Maps - Street View.

No se trata de una cuestión trivial. La diversificación y desestacionalización son los componentes esenciales de un nuevo modelo de turismo y los esfuerzos para alcanzarlo van desde instancias europeas hasta las pequeñas entidades locales (Castel Gayán y Lacasa Vidal, 2012:142). Fundamental es la diversificación de la demanda y ese objetivo se concreta en diversificación geográfica, temporal, motivacional y de la demanda. Al tiempo se insiste en la importancia de aumentar el poder de la marca turística (Turespaña, 2015:4). Cierto es que un destino turístico no debe limitar sus esfuerzos competitivos en sus recursos (Muñoz Mazón y Fuentes Moraleda, 2013:200) pero también lo es que el municipio o el pueblo a mayor altitud de España pueden tener un estupendo argumento de partida para el diseño y explotación de una marca turística. 
Es el turismo una posibilidad básica de inyección económica y de generación de empleo. Y en esa competencia por ganar turistas, la eficacia pasa por la diferenciación, explotando los valores locales singulares (Friedman, 2003; citado por Alameda y Fernández, 2012:2). La marca es la seña de identidad de una empresa, un producto, un servicio y también de un territorio (González Oñate y Martínez Bueno, 2013:113). La altitud es un aspecto geográfico que puede ser la base perfecta para la creación de una marca territorial, de una imagen exclusiva. No en vano, "la geografía es la gran abastecedora de los componentes básicos de las marcas turísticas" (García-Escudero, 2015).

Figura 3

CARTEL A LA ENTRADA DE VALDELINARES (TERUEL) POR LA CARRETERA TE-V-3: "VALDELINARES. MUNICIPIO MAS ALTO DE ESPAÑA. 1.692 METROS DE ALTITUD"

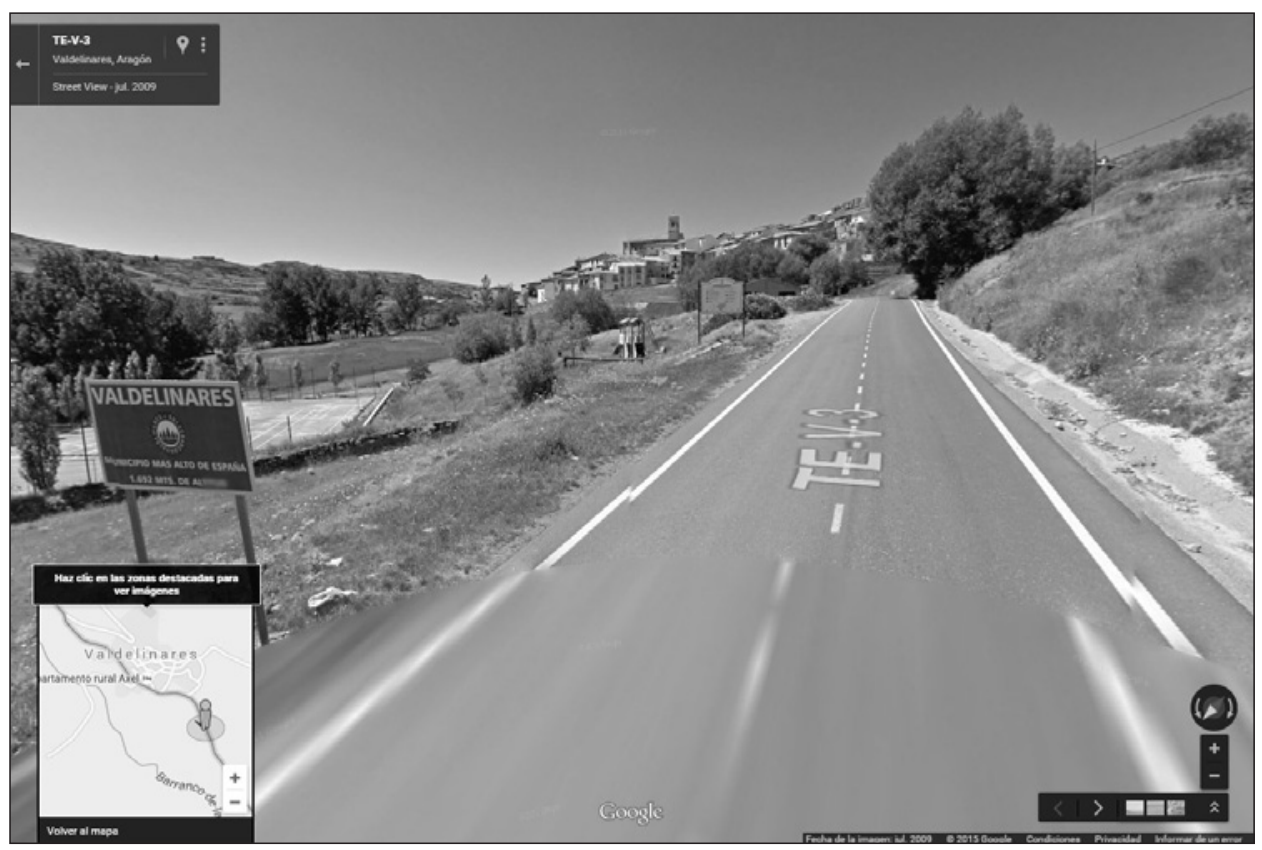

Fuente: Google Maps - Street View.

El Instituto Geográfico Nacional aporta luz al respecto de nuestro objeto de estudio con su Nomenclátor Geográfico de Municipios y Entidades de Población (Centro Nacional de Información Geográfica). Con altitudes extraídas de su modelo digital del terreno a resolución de 5 metros en las coordenadas geográficas del centroide, es decir, el punto más centrado posible en el núcleo poblacional (Ministerio de Fomento, 2015), el núcleo cabecera municipal más alto de España es Valdelinares con 1.695 metros.

Sin embargo, el mismo Nomenclátor señala 16 entidades por encima de los 1.695 metros de altitud y al menos 10 de ellas cuentan con población, según los datos del Instituto Nacio- 
nal de Estadística, recogidos por el citado documento. La más elevada aunque sin población es el observatorio de Izaña, Güímar en Santa Cruz de Tenerife, a 2.377 metros. Es la entidad más alta de España. Apenas dos personas constituyen el poblamiento oficial de la Estació d'Esquí Vallter 2000 en Setcases, Gerona. A 2.160 metros es la entidad con población oficial situada a mayor altitud de nuestro país. Cuatro habitantes y a 2.133 metros encontramos en Las Cañadas del Teide, La Orotava, Santa Cruz de Tenerife y 16 a los 1.931 metros de la estación leridana de Super Espot, Espot, Lérida. 92 habitantes, población prácticamente idéntica a Valdelinares y a una altitud cercana, 1.704 metros, pueblan el Port del Comte, en la Coma i La Pedra, Lérida. Pero Sierra Nevada en Monachil, Granada, a una altitud de 2.040 metros cuenta con 216 habitantes, 116 viven a los 1.812 metros del Puerto de Navacerrada, Cercedilla, Madrid y hasta 1.066 en Cueva del Agua, Iznalloz (Granada), 1.764 metros.

El presente estudio pretende aportar nuevos datos a esta cuestión, aprovechando los sistemas de información geográfica y la ingente cantidad de material disponible a raíz de la aplicación de la directiva europea INSPIRE. Se plantea distinguir entre municipio y pueblo y definir la altitud no sólo a partir de un punto concreto sino también con la media de las altitudes medidas en pueblos y municipios, entidades con superficie, por tanto polígonos, no puntos.

Como paso previo al análisis, definiremos el objeto del estudio, o mejor, los objetos. Pierre George, en su Diccionario de Geografía tan solo aborda el núcleo urbano, sin hacer mención a núcleos rurales o de forma genérica a los núcleos de población. El núcleo urbano sería la "parte central e histórica de las ciudades. Encrucijada de las vías principales, lugar de reunión de las actividades de dirección y de comercio al por menor de alto nivel (comercio de lujo), lugar de atracción turística (monumentos, espectáculos, hoteles, restaurantes, etc.).” (George, 2007: 420). Por eliminación, se considerará como núcleo rural la misma parte central, pero de un asentamiento que no alcanza la categoría de ciudad, y por extensión el núcleo de población será la parte central de cualquier asentamiento humano. Con mayor simpleza la Real Academia de la Lengua lo define como "agrupación de viviendas". Por su parte, pueblo es una "aglomeración rural cuya población incluye una proporción importante de agricultores" (George, 2007: 491) o una "población de menor categoría” (Real Academia de la Lengua). Por todo ello, para identificar el pueblo situado a mayor altitud de España, la base de datos que mejor se ajusta es la de los núcleos de población. Incluye todos los núcleos, rurales o urbanos y sus pedanías. Se han empleado las capas del Ministerio de Agricultura, Alimentación y Medio Ambiente (MAGRAMA) y del Centro Nacional de Información Geográfica (CNIG).

Por su parte, el término municipal es la "porción de territorio sometido a la autoridad de un ayuntamiento" y municipio sería el "conjunto de habitantes de un mismo término jurisdiccional, regido por un ayuntamiento" (Real Academia de la Lengua). La Ley 7/1985, de 2 de abril, reguladora de las Bases del Régimen Local, en su Título II, artículo 11 define el municipio como "la entidad local básica de la organización territorial del Estado. Tiene personalidad jurídica y plena capacidad para el cumplimiento de sus fines. Son elementos del Municipio el territorio, la población y la organización”. El artículo 12 define el territorio en línea similar a la Real Academia de la Lengua: "el territorio en que el ayuntamiento ejerce sus competencias" (Ley 7/1985, de 2 de abril).

Por tanto, se considerará el municipio como la totalidad del territorio y el pueblo como la capital de ese territorio, la superficie con construcciones humanas desde 
donde se dirige el municipio. Además, el estudio analizará la totalidad de los núcleos de población para observar los cambios que pueda introducir el poblamiento disperso.

\section{FUENTES}

Existe una gran cantidad de datos de libre acceso a nivel estatal. Un hito destacado en esa disponibilidad fue la directiva europea Inspire, Infrastructure for Spatial Information in Europe. La directiva marcaba las reglas para el establecimiento de una infraestructura de Información Espacial en los países de la Unión Europea. Se aprobó el 14 de marzo de 2007 y entró en vigor el 25 de abril del mismo año, cuando se publica en el Diario Oficial de la Unión Europea. En España la directiva se desarrolla a través la ley 14/2010, de 5 de julio, sobre las infraestructuras y los servicios de información geográfica en España, LISIGE (Consejo Superior Geográfico).

La mención de los datos empleados en este estudio da una idea del enorme esfuerzo realizado a raíz de la aplicación de la directiva Inspire (cuadro 1).

\section{Cuadro 1}

\section{DATOS EMPLEADOS Y SUS CARACTERÍSTICAS BÁSICAS}

\begin{tabular}{|c|c|c|c|c|c|}
\hline Datos & Centro & Descripción & Tipo & Coordenadas & Proyección \\
\hline MDT200 & CNIG & $\begin{array}{l}\text { Altitudes } \\
\text { Península y } \\
\text { Baleares }\end{array}$ & Ráster & EPSG:25830, ETRS89 & $\begin{array}{c}\text { UTM } \\
\text { zone } 30 \mathrm{~N}\end{array}$ \\
\hline MDT200 & $\mathrm{CNIG}$ & $\begin{array}{l}\text { Altitudes } \\
\text { Canarias } \\
\end{array}$ & Ráster & EPSG:4083, REGCAN95 & $\begin{array}{c}\text { UTM } \\
\text { zone } 28 \mathrm{~N}\end{array}$ \\
\hline $\begin{array}{l}\text { ASTER } \\
\text { GDEM }\end{array}$ & ERSDAC & Altitudes & Ráster & EPSG:4326, WGS84 & Geográficas \\
\hline Recintos & $\mathrm{CNIG}$ & $\begin{array}{l}\text { Límites } \\
\text { Península y } \\
\text { Baleares }\end{array}$ & Vector & EPSG:4258, ETRS89 & Geográficas \\
\hline Recintos & $\mathrm{CNIG}$ & $\begin{array}{l}\text { Límites } \\
\text { Canarias }\end{array}$ & Vector & EPSG:4326, WGS84 & Geográficas \\
\hline Municipios & ArcGIS & Municipios & Vector & EPSG:25830, ETRS89 & $\begin{array}{c}\text { UTM } \\
\text { zone } 30 \mathrm{~N}\end{array}$ \\
\hline Provincias & ArcGIS & Provincias & Vector & EPSG:25830, ETRS89 & $\begin{array}{c}\text { UTM } \\
\text { zone } 30 \mathrm{~N}\end{array}$ \\
\hline $\begin{array}{c}\text { Comunidades } \\
\text { autónomas }\end{array}$ & ArcGIS & $\begin{array}{c}\text { Comunidades } \\
\text { autónomas }\end{array}$ & Vector & EPSG:25830, ETRS89 & $\begin{array}{c}\text { UTM } \\
\text { zone } 30 \mathrm{~N}\end{array}$ \\
\hline Núcleos & MAGRAMA & Poblaciones & Vector & EPSG:4258, ETRS89 & Geográficas \\
\hline BTN 100 & $\mathrm{CNIG}$ & Poblaciones & Vector & EPSG:4258, ETRS89 & Geográficas \\
\hline BTN 100DIS & CNIG & $\begin{array}{l}\text { Población } \\
\text { diseminada }\end{array}$ & Vector & EPSG:4258, ETRS89 & Geográficas \\
\hline
\end{tabular}

En primer lugar tenemos el modelo digital del terreno con resolución de 200 metros, MDT200 (figura 4), disponible por provincias, en la web de descargas del Centro Nacional 
de Información Geográfica. Son cincuenta ficheros cuyas características se describen en un archivo de Metadatos. Se encuentran en formato ASCII matriz ESRI (asc). El sistema geodésico de referencia es el EPSG:25830, ETRS89 / UTM zone 30N, excepto en Canarias donde se usa el EPSG:4083, REGCAN95 / UTM zone 28N, compatible con el citado ETRS89. A raíz del Real Decreto 1071/2007 es el sistema de referencia geodésico oficial en España, siguiendo la recomendación de la Subcomisión de la Asociación Internacional de Geodesia (IAG) para el marco de referencia europeo (EUREF) (Instituto Geográfico Nacional). La proyección es la UTM en el huso de cada provincia, además de en el huso 30 extendido, para aquellas provincias a las que corresponde el huso 29 y 31 . Descargados y descomprimidos los 50 ficheros, se usarán aquellos correspondientes al huso 30, excepto los de las dos provincias canarias, situadas en el huso 28. Este modelo digital del terreno se ha interpolado de otros más precisos, con 5 metros de malla, procedentes del Plan Nacional de Ortofotografía Aérea (PNOA).

\section{Figura 4 \\ MODELO DIGITAL DEL TERRENO CON RED DE MALLA DE 200 METROS}

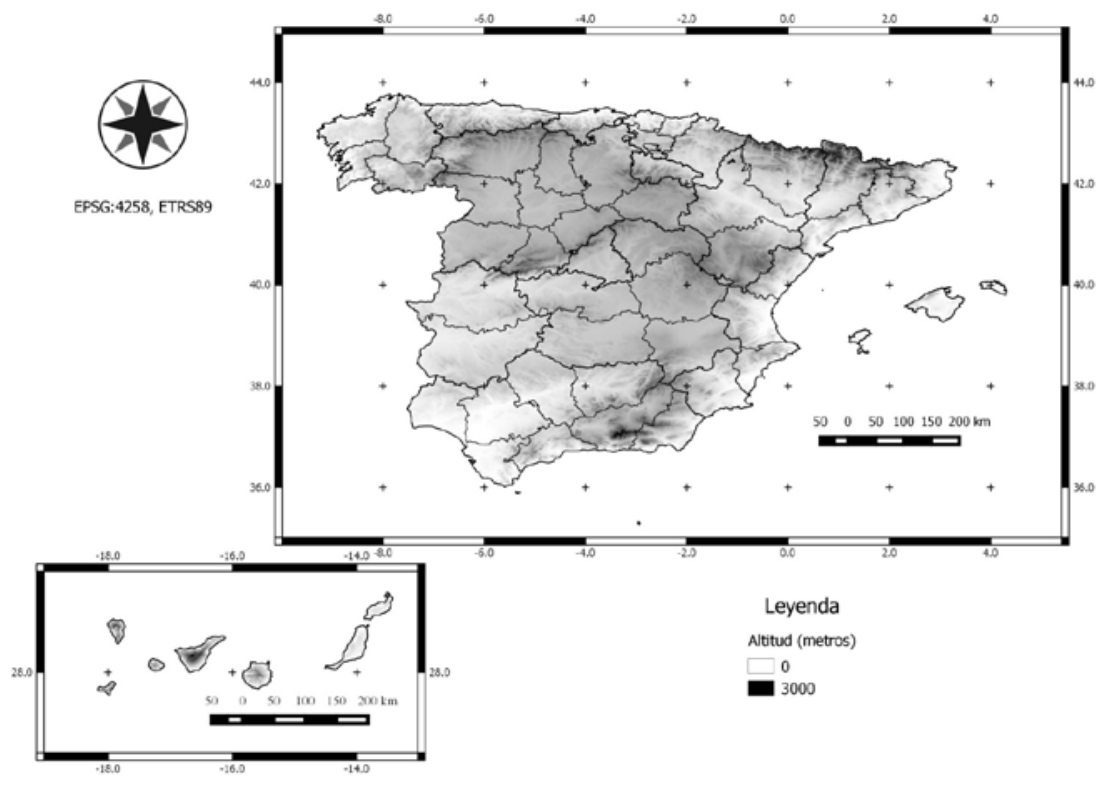

Fuente: Centro Nacional de Información Geográfica, Arcgis y elaboración propia.

En cuanto a los datos de altitud, la referencia en la Península es el nivel medio del mar en Alicante, mientras que en los archipiélagos es el nivel medio del mar en cada grupo de islas. Para Ceuta y Melilla, se toma el nivel medio del mar Mediterráneo.

Se escoge el MDT200 para que el volumen de datos a manejar en los más de 500.000 kilómetros cuadrados del territorio español no sea excesivo. Sin embargo, se compara con otro modelo digital del terreno, el ASTER GDEM. Se trata de un producto desarrollado y 
puesto a disposición por el Ministerio de Economía, Comercio e Industria japonés (METI) y la United States National Aeronautics and Space Administration, la conocida NASA. El nombre deriva del ASTER, Advanced Spaceborne Thermal Emission and Reflection Radiometer, el instrumento de observación. Es el único modelo digital de elevaciones que abarca todo el planeta en alta resolución. Su malla es de 30 metros y su sistema de coordenadas es el WGS84 (Japan Space Systems).

En cuanto a los ficheros vectoriales, los límites municipales, provinciales y autonómicos se han obtenido también del centro de descargas del Centro Nacional de Información Geográfica. Su sistema de coordenadas es el EPSG:4258, ETRS89 para la Península y Baleares y EPSG:4326, WGS84 para Canarias.

Sin embargo, el cálculo de altitudes con estos ficheros generó un problema derivado de entidades territoriales diferenciadas pero que no aparecen en las listas de municipios por provincias (Instituto Nacional de Estadística). Un ejemplo muy significativo es el de Los Baldíos, en Madrid, que estaba individualizado en el fichero del Centro Nacional de Información Geográfica y con 1.594 metros era el tercer "municipio" con núcleos de población más elevados de España pero que realmente pertenece al municipio de Cercedilla. Por ello, se recurre a los ficheros vectoriales de límites administrativos que se encuentran en la web de ArcGIS (figura 5). Su sistema de coordenadas es el EPSG:4258, ETRS89.

\section{Figura 5 \\ CARTOGRAFÍA DE LOS LÍMITES MUNICIPALES, PROVINCIALES Y AUTONÓMICOS}

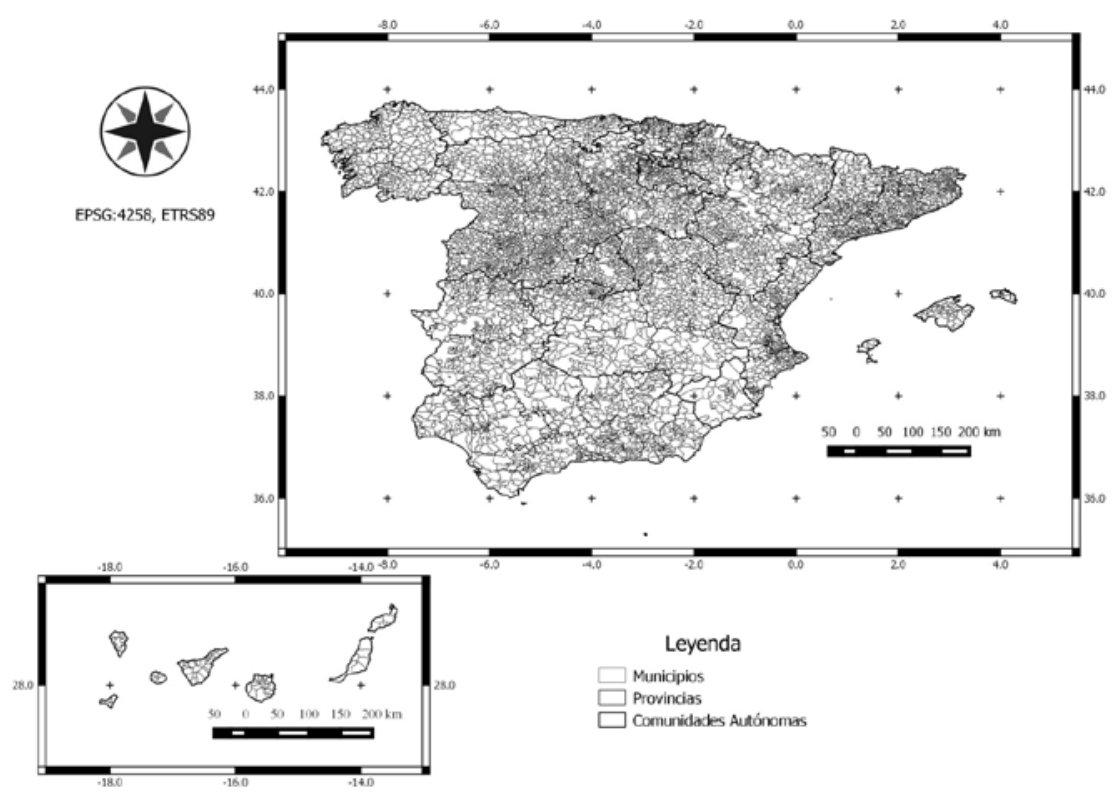

Fuente: Arcgis y elaboración propia. 
Por último pero no menos importante se utilizan los núcleos de población, con una doble fuente: el Centro Nacional de Información Geográfica aporta el fichero base que se complementa con el descargado desde la web del Ministerio de Agricultura, Alimentación y Medio Ambiente (MAGRAMA). En ambos casos, su sistema de coordenadas, EPSG:4258, ETRS89.

\section{MÉTODOS}

Los sistemas de información geográfica constituyen una perfecta herramienta para el análisis territorial. Siendo el turismo una actividad con un importante impacto espacial y dependiendo un producto turístico de una variedad de factores físicos (relieve, clima, vegetación, agua) y humanos (económicos, técnicos, sociales, políticos), susceptibles de localización espacial y de complejas interacciones, la consecuencia lógica es que los sistemas de información geográfica tengan multitud de aplicaciones en el ámbito turístico, al permitir representar esos factores sobre una base cartográfica y analizar las citadas interacciones. Así queda reflejado en numerosos estudios que abarcan desde la relación general de los SIG con el turismo (Lobo Montero, 1999; Luaces et al., 2008) hasta investigaciones concretas acerca de potencialidades y promoción (Chiquillo, 2013; Benítez López et al., 2014; Cerezo y Galacho, 2011; Dye y Shaw, 2007; Gill y Bharath, 2013; Jovanovic y Njegus, 2013), planificación (Sánchez Martín et al., 2000; Sobral, 2008; Chancellor y Cole, 2008; Constantoglou, 2009), materialización (Sánchez Rivero, 2008; Mínguez García et al., 2015; Rengifo Gallego, 2013) y consecuencias (García Cruz, 2015).

Nuestro estudio trata de aprovechar las enormes potencialidades de los sistemas de información geográfica. Los datos serán tratados y analizados con el software QGIS. Inicialmente conocido como Quantum GIS, comenzó en 2002 y hoy día es el sistema de información geográfica líder de código abierto para escritorio. Es un proyecto de la Open Source Geospatial Foundation (OSGeo), impulsado por voluntarios que constituyen una creciente comunidad de desarrolladores. Actualmente la versión más moderna es el QGIS 2.12 Lyon.

El proceso (figura 6) comienza con la unión de las diferentes hojas para generar un modelo digital del terreno para la Península y Baleares por un lado y Canarias por el otro, ya que los datos ráster vienen en sistemas de coordenadas distintos. Para ello se utiliza la herramienta "Combinar". Los ficheros se crean con los sistemas de coordenadas correspondientes a los modelos y especificados en sus metadatos: EPSG:25830, ETRS89 / UTM zone 30N para Península y Baleares y EPSG:4083, REGCAN95 / UTM zone 28N, para el archipiélago canario. El modelo del terreno en Canarias, con la función "Combar", se pasa al EPSG:25830, ETRS89 / UTM zone 30N del resto de España, como paso previo a integrar ambos modelos del terreno en uno solo. Éste es el objetivo de aplicar de nuevo la herramienta "Combinar". Un proceso más simple, limitado a combinar los ficheros ráster originales, se ha empleado para crear el modelo digital del terreno con malla de 30 metros.

Finalmente, los ficheros se trasladan a un sistema de coordenadas EPSG:4258, ETRS89, basada en coordenadas geográficas de latitud y longitud frente a las Universal Tranversal Mercator (UTM) del ETRS89 / UTM zone 30N. El modelo de coordenadas geográficas facilita la representación de la Península y los dos archipiélagos. 


\section{Figura 6 \\ PROCESO CARTOGRÁFICO SEGUIDO EN EL ESTUDIO}

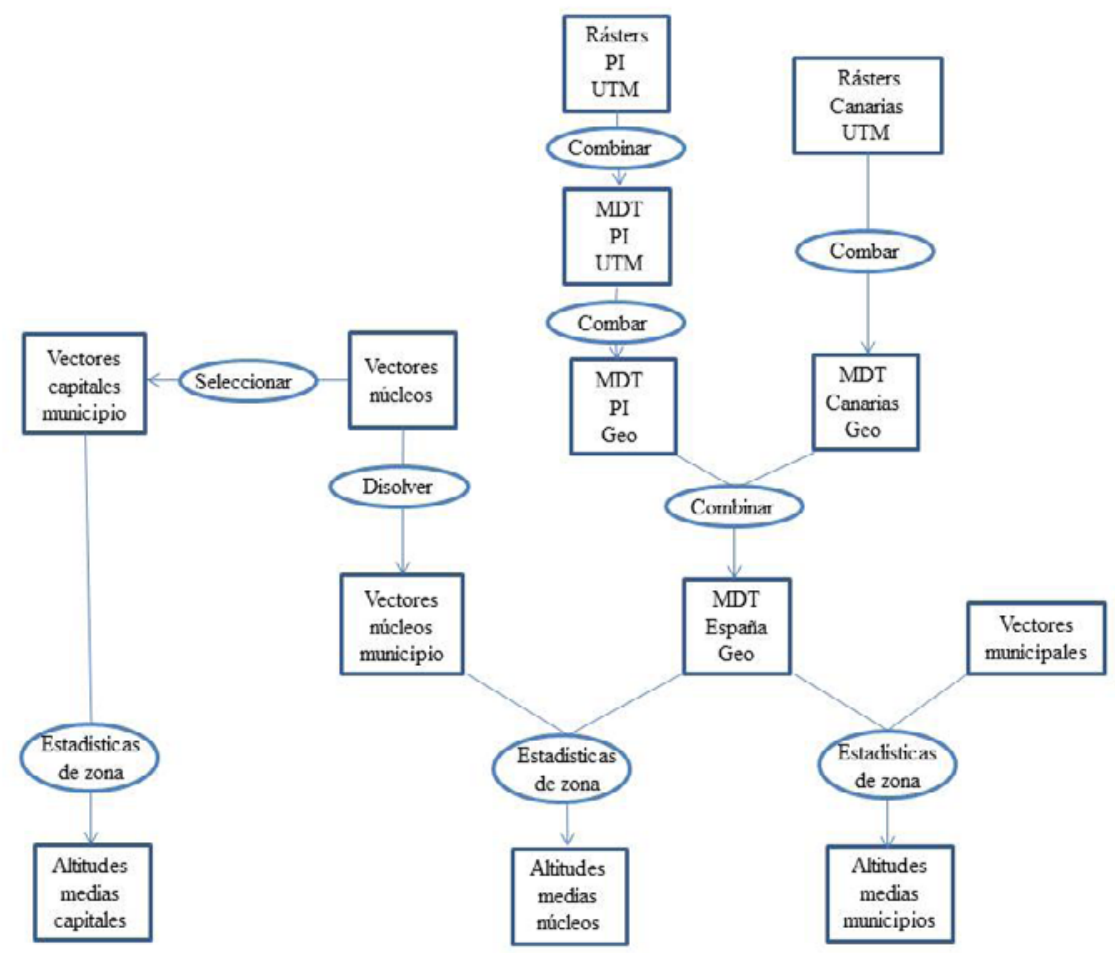

La obtención de las medias de altitud para los municipios españoles se realiza con la herramienta "Estadísticas de zona". El procesamiento crea en la tabla de atributos de la capa vectorial varias columnas con los estadísticos de la altitud para cada municipio: el número de píxeles incluido en cada polígono, en este caso, municipios; la suma de los valores, un elemento que no aporta ninguna información útil para nuestro estudio, la media, el valor más destacado, la mediana, la desviación estándar, el mínimo, máximo, intervalo, minoría, mayoría y variedad.

Un proceso parecido se ha aplicado al fichero de núcleos de población, perteneciente a la base topográfica a escala 1:100.000, descargado del CNIG. Aquellos municipios sin núcleos de población, se han completado con el fichero del MAGRAMA. La capa resultante permitirá conocer las altitudes de los pueblos. Al fichero original se le añaden los atributos de municipio con "Unir atributos por localización". Se calculan las altitudes con "Estadísticas de Zona". El resultado será un valor para cada uno de los núcleos de población, incluidas las capitales municipales. Para conocer las altitudes municipales de los núcleos de población se ha aplicado la herramienta "disolver" para unir los distintos núcleos de un municipio en un solo objeto y a continuación se aplica de nuevo "Estadísticas de Zona”. 


\section{RESULTADOS}

El primer análisis recae sobre las medias de los municipios, una medida más adecuada para decidir la altitud de dichas entidades que un simple punto de ubicación más o menos aleatoria. Como dato significativo reseñar que hay 31 municipios con altitudes medias por encima de los 1.800 metros. Sus altitudes medias se han calculado sobre un total de 106.649 puntos en el caso del Modelo Digital del Terreno a 200 metros de malla y sobre más de 5 millones de puntos (5.623.297) en el modelo de 30 metros de malla.

Figura 7

MAPA DE ALTITUD MEDIA POR MUNICIPIOS (MDT200)

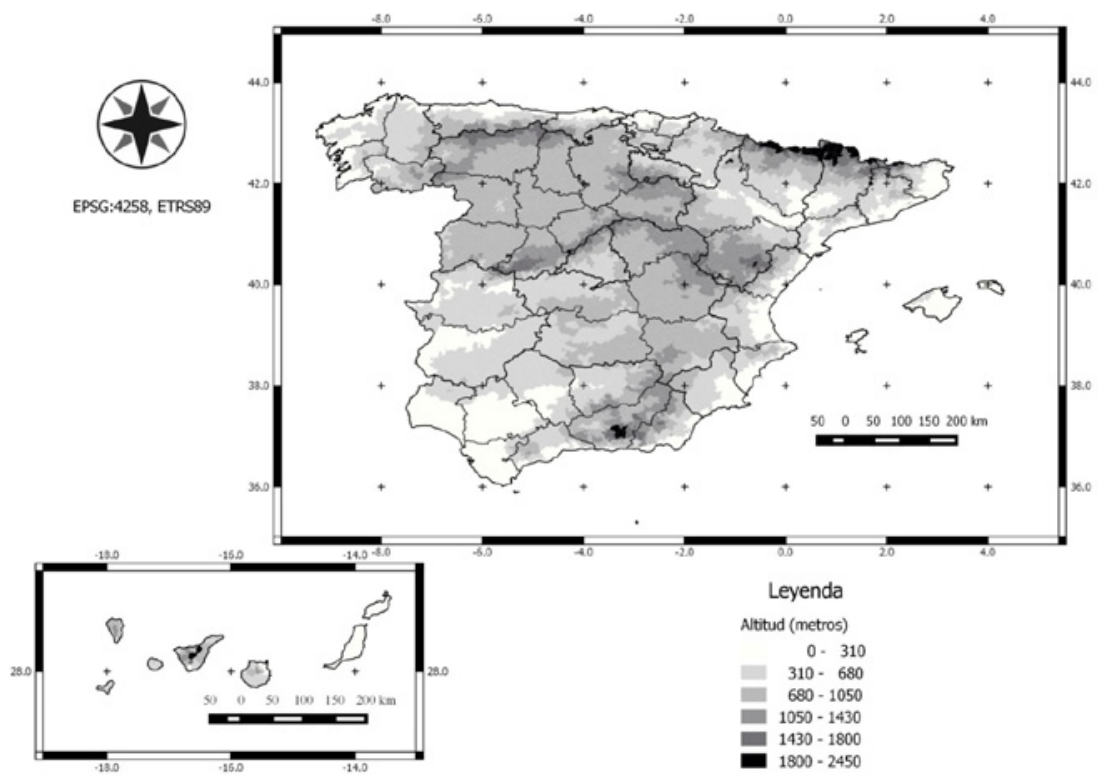

Fuente: Centro Nacional de Información Geográfica, Arcgis y elaboración propia.

Los resultados (figura 7 y cuadro 2) cambian la clasificación de la altitud municipal de forma radical respecto de aquellos reflejados por el Nomenclátor Geográfico de Municipios y Entidades de Población y muestran un claro dominio de las dos cordilleras más elevadas de España, los Pirineos y las Béticas. De esos 31 municipios, 29 se localizan en los Pirineos (10 en Huesca, 9 en Lérida y 3 en Gerona) y las Béticas ( 7 municipios granadinos). Sólo dos escapan a este dominio, La Orotava en Santa Cruz de Tenerife y Valdelinares en Teruel, que es el municipio que cierra la tabla. Quince superan los 2.000 metros, incluidos, por supuesto, los que configuran el pódium: los granadinos de Trevélez, Capileira y el oscense de Benasque. Los tres se benefician de contar total o parcialmente en su territorio con picos de renombre: los dos granadinos comparten con Güejar-Sierra la mayor altitud peninsular, el Mulhacén, pero mientras los dos primeros extienden su 
territorio por la sierra, el último acaba en la vega granadina, lo que reduce su promedio. Por su parte, el Aneto, el segundo pico de la Península y mayor elevación pirenaica se localiza en Benasque. En la misma línea, el único municipio canario del listado, La Orotava, posee la mayor altitud de España, El Teide. Sin duda, un municipio singular en tanto que incluye costa por lo que es indiscutiblemente el municipio con mayor desnivel del Estado.

\section{Cuadro 2}

MUNICIPIOS CON ALTITUD MEDIA POR ENCIMA DE LOS 1.800 METROS (MDT200 Y ASTER GDEM)

\begin{tabular}{|c|c|c|c|c|c|}
\hline \multirow{2}{*}{ Municipio } & \multirow{2}{*}{ Provincia } & \multicolumn{2}{|c|}{ MDT200 } & \multicolumn{2}{|c|}{ ASTER GDEM } \\
\hline & & Puntos & Altitud & Puntos & Altitud \\
\hline Trevélez & Granada & 2.272 & $2.431,77$ & 119.444 & $2.432,83$ \\
\hline Capileira & Granada & 1.415 & $2.352,84$ & 74.730 & $2.356,43$ \\
\hline Benasque & Huesca & 6.315 & $2.219,93$ & 332.590 & $2.226,45$ \\
\hline Meranges & Gerona & 1.014 & $2.134,09$ & 53.305 & $2.132,63$ \\
\hline Espot & Lérida & 2.614 & $2.130,66$ & 138.180 & $2.120,93$ \\
\hline San Juan de Plan & Huesca & 1.497 & $2.128,91$ & 79.089 & $2.130,47$ \\
\hline Gistaín & Huesca & 2.076 & $2.118,58$ & 109.611 & $2.118,21$ \\
\hline Queralbs & Gerona & 2.523 & $2.110,77$ & 133.420 & $2.110,37$ \\
\hline Vall de Boí (La) & Lérida & 5.926 & $2.080,18$ & 312.344 & $2.080,43$ \\
\hline Panticosa & Huesca & 2.593 & $2.065,06$ & 136.607 & $2.063,00$ \\
\hline Bubión & Granada & 368 & $2.060,38$ & 19.580 & $2.057,67$ \\
\hline Naut Aran & Lérida & 6.887 & $2.052,89$ & 363.284 & $2.055,22$ \\
\hline Lladorre & Lérida & 3.992 & $2.048,29$ & 210.996 & $2.044,55$ \\
\hline Sahún & Huesca & 1.965 & $2.032,89$ & 103.441 & $2.037,75$ \\
\hline Bérchules & Granada & 1.735 & $2.031,33$ & 91.153 & $2.045,51$ \\
\hline Lles de Cerdanya & Lérida & 2.774 & $1.984,47$ & 146.162 & $1.977,01$ \\
\hline Alins & Lérida & 5.001 & $1.981,75$ & 263.067 & $1.979,77$ \\
\hline Alt Àneu & Lérida & 5.863 & $1.972,06$ & 309.396 & $1.967,65$ \\
\hline Setcases & Gerona & 1.312 & $1.943,54$ & 69.145 & $1.944,11$ \\
\hline Sallent de Gállego & Huesca & 4.383 & $1.941,97$ & 231.087 & $1.936,88$ \\
\hline Pórtugos & Granada & 510 & $1.938,23$ & 27.005 & $1.949,01$ \\
\hline Bielsa & Huesca & 5.456 & $1.920,20$ & 288.057 & $1.921,01$ \\
\hline Canfranc & Huesca & 1.937 & $1.913,93$ & 101.890 & $1.912,28$ \\
\hline Torla & Huesca & 5.016 & $1.889,67$ & 263.741 & $1.891,90$ \\
\hline Güejar Sierra & Granada & 5.958 & $1.886,96$ & 314.156 & $1.887,49$ \\
\hline Vielha e Mijaran & Lérida & 5.701 & $1.872,37$ & 300.561 & $1.876,60$ \\
\hline Orotava (La) & S.C. de Tenerife & 4.632 & $1.871,46$ & 244.385 & $1.877,22$ \\
\hline Montanuy & Huesca & 4.714 & $1.836,70$ & 248.589 & $1.837,39$ \\
\hline Jerez del Marquesado & Granada & 2.068 & $1.824,19$ & 108.965 & $1.831,15$ \\
\hline Torre de Cabdella (La) & Lérida & 4.449 & $1.822,16$ & 234.823 & $1.815,25$ \\
\hline Valdelinares & Teruel & 1.431 & $1.808,07$ & 75.697 & $1.803,81$ \\
\hline
\end{tabular}

Fuente: Centro Nacional de Información Geográfica, Meti, Nasa, Arcgis y elaboración propia. 
Con el fin de dotar de mayor precisión a los resultados, se procede a recalcular los promedios a partir del modelo digital del terreno de mayor precisión, el ASTER GDEM. No hay cambios significativos en los principales municipios con el modelo más preciso, lo que prueba la fiabilidad del MDT200. En promedio las altitudes difieren 4,26 metros y la mayor disparidad alcanza los 14 metros. Varios municipios alternan su posición en la clasificación, pero nunca entre los cuatro primeros por lo que se confirma la condición de Trevélez como el municipio con mayor altitud de España.

En cuantos a los pueblos se calculan las altitudes de las capitales municipales, aprovechando los ficheros vectoriales extraídos del CNIG y MAGRAMA y el Modelo Digital de malla de 200 metros. En este caso no se aplicará el modelo de 30 metros de malla, visto que no modifica los resultados. Las medias se obtienen de todos los puntos de malla en las distintas localidades y evita discusiones que surgen cuando la altitud se decide a partir de un solo punto (figura 8).

Figura 8

MAPA MUNICIPAL DE ALTITUD MEDIA DE LOS PUEBLOS (MDT200)

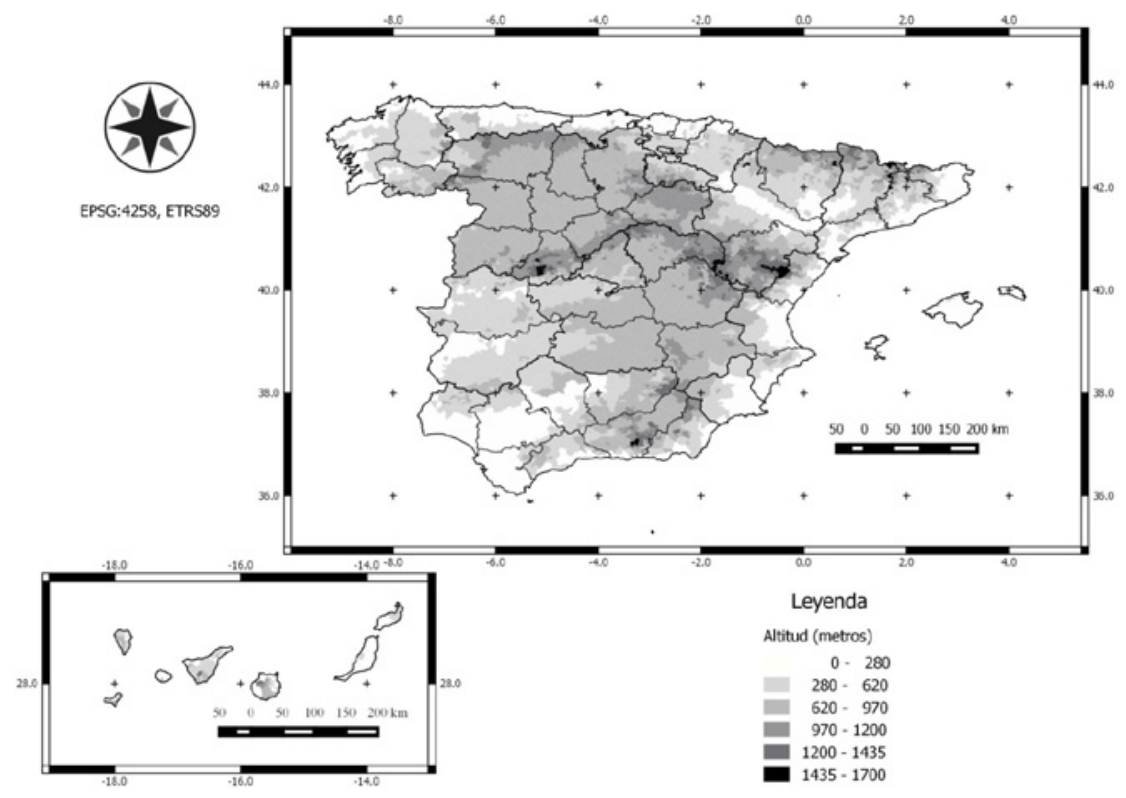

Fuente: Centro Nacional de Información Geográfica, Arcgis y elaboración propia.

El cuadro 3 recoge los primeros 31 municipios, aquellos cuyas capitales alcanzan una altitud media por encima de los 1.435 metros. Un número similar al mostrado para los municipios, a fin de favorecer la comparación espacial. Efectivamente, su distribución es totalmente diferente. Ahora desaparece el peso hipsográfico de los grandes picos, ya que los núcleos de población no muestran hipsotropía y prefieren valles y laderas. Por tanto, 
las grandes cordilleras prácticamente desaparecen en el mapa y el predominio se centra en municipios ubicados en unidades más modestas: La Cordillera Central y la Ibérica. Los turolenses son los dominantes. Hasta trece, tanto del ramal aragonés como del castellano de la Cordillera Ibérica, a los que se suma, en ese último, uno caracense. La Cordillera Central aglutina diez municipios abulenses, reflejando la principal vertebra de la cordillera, la Sierra de Gredos, y la Sierra de Ávila, de menor entidad; y el madrileño de Somosierra. Del dominio pirenaico y penibético en el ranking de los municipios tan sólo quedan pequeños retazos, en Gerona, Huesca y Lérida, por un lado, y en Granada, por el otro. En cuanto a Canarias ningún municipio tiene la altitud media de sus poblaciones por encima de los 1.435 metros. Sólo tres superan los 1.000 metros: Vilaflor (1.242,50 metros), Santa Cruz de Tenerife, y los gran canarios Vega de San Mateo y Tejeda, 1.145,83 y 1.053,58 respectivamente.

Esta diferencia se ejemplifica muy bien en el cuadro de honor. Frente al granadino Trevélez, la cumbre en los pueblos lo consigue el otro municipio en discordia, Valdelinares en Teruel. Sus acompañantes son también turolenses, Griegos y Bronchales. Nada que ver con el pódium municipal compartido por lugares de Huesca y Granada.

La comparativa con el Nomenclátor Geográfico de Municipios y Entidades de Población arroja mínimas diferencias. El Nomenclátor obtiene una sola altitud, el centroide, para cada núcleo de población principal, mientras nuestro sistema recoge todos los puntos de todos los pueblos, lo que repercute en ligeras diferencias de resultados y por tanto de clasificación. La variación más significativa es que Gúdar supera a Bronchales en el Nomenclátor y entra en el pódium. Sin embargo, la distribución espacial es similar, concentrada en la Cordillera Ibérica y Central. Incluso los protagonistas son prácticamente los mismos: 29 de los 31 pueblos más elevados de España coinciden.

\section{Cuadro 3}

\section{MUNICIPIOS CON ALTITUDES MEDIAS DE SUS PUEBLOS POR ENCIMA DE LOS 1.435 METROS (MDT200)}

\begin{tabular}{|l|c|c|c|}
\hline Municipio & Provincia & Puntos & Altitud \\
\hline Valdelinares & Teruel & 5 & $1.694,96$ \\
\hline Griegos & Teruel & 4 & $1.602,93$ \\
\hline Bronchales & Teruel & 11 & $1.588,07$ \\
\hline Gúdar & Teruel & 2 & $1.578,00$ \\
\hline Guadalaviar & Teruel & 3 & $1.544,64$ \\
\hline Navarredonda de Gredos & Ávila & 9 & $1.536,32$ \\
\hline Hoyos de Miguel Muñoz & Ávila & 2 & $1.530,58$ \\
\hline Navaquesera & Ávila & 3 & $1.528,36$ \\
\hline Meranges & Gerona & 2 & $1.524,90$ \\
\hline Navadijos & Ávila & 3 & $1.518,30$ \\
\hline Hoyos del Collado & Ávila & 2 & $1.508,35$ \\
\hline
\end{tabular}




\begin{tabular}{|l|c|c|c|}
\hline Orea & Guadalajara & 3 & $1.502,56$ \\
\hline Cepeda la Mora & Ávila & 3 & $1.500,26$ \\
\hline Trevélez & Granada & 6 & $1.498,90$ \\
\hline San Martín de la Vega del Alberche & Ávila & 9 & $1.491,92$ \\
\hline Toril y Masegoso & Teruel & 2 & $1.488,84$ \\
\hline Frías de Albarracín & Teruel & 4 & $1.483,13$ \\
\hline Mosqueruela & Teruel & 7 & $1.480,43$ \\
\hline Lles de Cerdanya & Lérida & 3 & $1.466,70$ \\
\hline Garganta del Villar & Ávila & 2 & $1.465,19$ \\
\hline Terriente & Teruel & 4 & $1.457,18$ \\
\hline Capileira & Granada & 3 & $1.455,85$ \\
\hline Puertomingalvo & Teruel & 5 & $1.453,44$ \\
\hline Monteagudo del Castillo & Teruel & 4 & $1.452,19$ \\
\hline Orihuela del Tremedal & Teruel & 11 & $1.451,32$ \\
\hline Hoyos del Espino & Ávila & 11 & $1.449,65$ \\
\hline Villanueva del Campillo & Ávila & 5 & $1.444,84$ \\
\hline Somosierra & Madrid & 5 & $1.437,05$ \\
\hline Vallecillo (EI) & Teruel & 3 & $1.436,72$ \\
\hline Gósol & Ávila & 5 & $1.435,30$ \\
\hline Lospaúles & Huesca & 2 & $1.435,30$ \\
\hline
\end{tabular}

Fuente: Centro Nacional de Información Geográfica, Arcgis y elaboración propia.

En caso de considerar todos núcleos de población de un municipio y no tan sólo la capital, el mapa dibujado es idéntico y como en la comparación anterior tan sólo habría que matizar ligeras variaciones en los resultados. Municipios antes ausentes aparecen ahora, caso de La Coma i La Pedra (Lérida), Aisa (Huesca) y San Juan de Gredos (Ávila), gracias a núcleos de elevada altitud, por encima de los 1.500 metros. Destacado es el caso de La Coma i La Piedra, que con todos sus núcleos de población, sería el $5^{\circ}$ municipios más elevado, y en el que contrasta la altitud de su capital, 1.003 metros y la de su otro núcleo, El Port del Comte, a 1.639 metros, uno de los más elevados de España. Contraste parecido encontramos en Aisa, entre su capital y el núcleo de Candanchú.

Resuelta la confrontación sobre el pueblo y el municipio situados a mayor altitud de España, aprovechamos la disponibilidad de datos para señalar los municipios y pueblos a mayor altitud de cada Comunidad Autónoma (cuadro 4). Como en el caso anterior, se pueden encontrar diferencias.

Los datos nos ofrecen pistas sobre el relieve español. En el norte, refleja la menor entidad de los Pirineos navarros frente a los aragoneses y catalanes, buena muestra de la disimetría longitudinal de la Cordillera. El umbral vasco, con menor altitud, da paso a la Cordillera Cantábrica, que prolonga sus elevaciones en Asturias, a las que se adosan las 
elevaciones orientales gallegas, que cierran la Meseta por el noroeste. Las vertebraciones de la Cordillera Central marcan las máximas altitudes de Extremadura, Castilla - León y Madrid, mientras que la Ibérica queda reflejada en La Rioja, Castilla - La Mancha y Comunidad Valenciana. Sierra Morena queda ensombrecida por los grandes picos de la Penibética. En Canarias, el Teide impone su dominio. Valores bajos muestran la Serra de Tramuntana en Baleares y la murciana comarca del Noroeste.

\section{Cuadro 4}

MUNICIPIOS CON SU TERRITORIO Y PUEBLOS CON ALTITUDES MEDIAS MÁS ELEVADAS POR COMUNIDADES AUTÓNOMAS

\begin{tabular}{|c|c|c|c|c|}
\hline CCAA & Municipio & Altitud & Núcleos & Altitud \\
\hline Andalucía & Trevélez & $2.431,77$ & Trevélez & $1.498,90$ \\
\hline Aragón & Benasque & $2.219,93$ & Valdelinares & $1.694,96$ \\
\hline Asturias & Somiedo & $1.300,68$ & Degaña & 845,95 \\
\hline Baleares & Escorca & 609,80 & Escorca & 481,47 \\
\hline Canarias & La Orotova & $1.871,46$ & Vilaflor & $1.412,04$ \\
\hline Cantabria & $\begin{array}{l}\text { Hermandad del Campoo } \\
\text { de Suso }\end{array}$ & $1.264,78$ & \begin{tabular}{|l|} 
Valdeprado Del \\
Río
\end{tabular} & 951,85 \\
\hline C. - León & Zapardiel de la Ribera & $1.700,03$ & \begin{tabular}{|l|}
$\begin{array}{l}\text { Navarredonda de } \\
\text { Gredos }\end{array}$ \\
\end{tabular} & $1.536,32$ \\
\hline C.-La Mancha & Orea & $1.615,94$ & Orea & $1.502,56$ \\
\hline Cataluña & Meranges & $2.134,09$ & Meranges & $1.524,90$ \\
\hline C. Valenciana & Puebla de San Miguel & $1.332,27$ & $\begin{array}{|ll|}\text { Vistabella del } \\
\text { Maestrazgo }\end{array}$ & $1.224,17$ \\
\hline Extremadura & Tornavacas & $1.519,10$ & Piornal & $1.179,87$ \\
\hline Galicia & Chandrexa de Queixa & $1.215,82$ & \begin{tabular}{|l}
$\begin{array}{l}\text { Pedrafita do } \\
\text { breiro }\end{array}$ \\
\end{tabular} & $1.148,97$ \\
\hline Madrid & Somosierra & $1.622,81$ & Somosierra & $1.437,05$ \\
\hline Murcia & Caravaca de la Cruz & 980,61 & Bullas & 633,87 \\
\hline Navarra & Isaba & $1.361,84$ & Abaurrea Alta & $1.040,48$ \\
\hline País Vasco & Abaltzisketa & 924,87 & Valle de Arana & 817,39 \\
\hline La Rioja & Viniegra de Arriba & $1.527,00$ & Viniegra de Arriba & $1.255,34$ \\
\hline
\end{tabular}

Fuente: Centro Nacional de Información Geográfica, arcgis y elaboración propia.

Los datos de los pueblos son menos significativos a la hora de identificar el relieve, dado que la ocupación humana tradicional huye de cualquier tendencia hipsotrópica. Las diferencias son más acusadas en las cordilleras que sufrieron retoques glaciares y en las que las laderas muestran mayores pendientes. Por tanto, es mayor el contraste altitudinal entre los picos y los valles donde se instalan las poblaciones. Así, el pueblo situado a 
mayor altitud de Aragón (y de España) no se localiza en el Pirineo sino en la Bética, sino en la Ibérica. El de mayor valor de Cataluña, en el Pirineo, queda al nivel del primero de Castilla - León, ubicado en la Cordillera central, una unidad de mucha menor entidad. O como las poblaciones más elevadas de Asturias y Cantabria quedan por debajo de los 1.000 metros, igual que la del País Vasco, a pesar que su cordillera es de mayor enjundia. Viniegra de Arriba, en la Ibérica riojana las supera con creces.

Al igual que ocurre en el caso estatal, el poblamiento disperso provoca algunas diferencias y si consideramos la totalidad de los núcleos de población hasta seis comunidades autónomas cambian su cima municipal. Son los casos de Cantabria (Valdeolea), Cataluña (La Coma i La Pedra), Baleares (Valdemosa), La Rioja (Lumbreras), Asturias (Somiedo) y Murcia (Moratalla). Sus núcleos dispersos a mayor altura que su cabecera municipal les aportan ventaja.

\section{CONCLUSIONES}

El presente estudio aprovecha el importante desarrollo de los Sistema de Información Geográfica de acceso libre y la gran cantidad de datos espaciales surgidos en España y el resto de Europa a raíz de la directiva Inspire para resolver una cuestión, el municipio y el pueblo con mayor altitud media de España, que inunda foros y redes sociales y de la cual apenas hay referencia científica y ninguna publicada en revistas de prestigio.

La diversificación y desestacionalización son los componentes de un nuevo modelo turístico. Esa diversificación geográfica, temporal, motivacional y de la demanda. Al tiempo se insiste en la importancia de aumentar el poder de la marca turística. El municipio o el pueblo a mayor altitud de España pueden tener un estupendo argumento de partida para el diseño y explotación de una marca turística. No en vano, la geografía es la gran abastecedora de los componentes básicos de las marcas turísticas.

Los sistemas de información geográfica constituyen una perfecta herramienta para el análisis territorial. Siendo el turismo una actividad con un importante impacto espacial y dependiendo un producto turístico de una variedad de factores espaciales y de complejas interacciones, los sistemas de información geográfica son de necesaria aplicación en el campo de los estudios turísticos, al representar sobre una base cartográfica tanto esos factores como sus interacciones.

En cuanto a los resultados, destaca su diversidad espacial. En los municipios prima la geografía física y así los más elevados se concentran principalmente en las dos cordilleras más importantes de España: Pirineos y Béticas. Por el contrario, en los pueblos se interponen motivaciones humanas. Las poblaciones escapan de las grandes altitudes lo que traslada los núcleos más elevados a cordilleras más modestas. La consideración en los cálculos de la totalidad de los núcleos de población no varía la distribución espacial de las altitudes y tan solo aporta ligeros retoques en los municipios protagonistas de los valores más elevados.

La consideración de las mayores altitudes autonómicas refleja las unidades del relieve español, al considerar la totalidad del municipio. No es el caso de los pueblos, en los que intervienen causas humanas en su ubicación, aspecto ya reflejado a nivel estatal. Hasta seis comunidades autónomas cambian su valor más elevado al calcular las altitudes de todos los núcleos de población y no solo de la cabecera municipal. Las diferencias son el esperado reflejo del poblamiento disperso. 
Finalmente, los principales municipios que se disputaban el honor de ser el más elevado de España, Trevélez y Valdelinares, o Valdelinares y Trevélez, han demostrado tener su cuota de razón. Según el objeto de estudio, ambos pueden recibir el puesto de honor en las altitudes españolas, si bien sería conveniente que sus autoridades municipales corrigieran sus diplomas identificativos, tal como muestran las figuras 2 y 3: el municipio debería ser para Trevélez; el pueblo, para Valdelinares.

\section{REFERENCIAS BIBLIOGRÁFICAS}

ALAMEDA, D., FERNÁNDEZ, E. (2012): «La comunicación de las marcas territorio». Actas IV Congreso Internacional Latina de Comunicación social. Universidad de La Laguna, pp. 1-28. Disponible en http://www.revistalatinacs.org/12SLCS/2012_actas.html ARCGIS. «Comunidades Autónomas - ETRS89 UTM 30N», 19 de agosto de 2015. Disponible en http://www.arcgis.com/home/item.html?id=5f689357238847bc823a2f b164544a77

ARCGIS. «Municipios - ETRS89 UTM 30N», 19 de agosto de 2015. Disponible en http:// www.arcgis.com/home/item.html?id=2e47bb12686d4b4b9d4c179c75d4eb78

ARCGIS. «Provincias - ETRS89 UTM 30N», 19 de agosto de 2015. Disponible en http:// www.arcgis.com/home/item.html?id=83d81d9336c745fd839465beab885ab7

AYUNTAMIENTO DE VALDELINARES. «El pueblo», 1 de agosto de 2015. Disponible en http://valdelinares.deteruel.es/InternetRural/valdelinares/home.nsf/menu/valdelinares_pueblo__historia

BENÍTEZ LÓPEZ, D., LÓPEZ SÁNCHEZ, J.A., ARCILA GARRIDO, M. (2014): «El uso de los SIG como herramienta para la actividad turística: el caso de la región Tánger-Tetuán», en Congreso universitario internacional Turismo en Andalucía y norte de Marruecos: nuevos retos, nuevas propuestas, Facultad de Turismo, Universidad de Málaga, pp. 55-65.

CASTEL GAYÁN, S., LACASA VIDAL, J. (2012): «Diversificación, desestacionalización y derecho del turismo». Revista Jurídica de Navarra, n 53-54, pp. 113-146.

CEREZO MEDINA, A., GALACHO JIMÉNEZ, F.B. (2011): «Propuesta metodológica con SIG para la evaluación de la potencialidad del territorio respecto a actividades ecoturísticas y de turismo activo. Aplicación en la Sierra de Las Nieves (Málaga, España)». Investigaciones Turísticas, $\mathrm{n}^{\circ} 1$, pp. 134-147.

CHANCELLOR, H.C., COLE, S.T. (2008): «Using geographic information system to visualize travel patterns and market research data». Journal of Travel and Tourism Marketing, vol. 25 (3/4), pp. 341-354.

CONSTANTOGLOU, M. (2009): «The creation of a supply tourism typology for the greek coastal area with the use of GIS and FcM for planning purposes». 4th International Scientific Conference:Planning for the Future - Learning from the Past: Contemporary Developments in Tourism, Travel \& Hospitality. University of the Aegean, Rodas (Grecia).

CENTRO NACIONAL DE INFORMACIÓN GEOGRÁFICA. «Centro de descargas Base topográfica nacional a escala 1:100.000 en formato shapefile», 24 de febrero de 2016. Disponible en http://centrodedescargas.cnig.es/CentroDescargas/ 
CENTRO NACIONAL DE INFORMACIÓN GEOGRÁFICA. «Centro de descargas Líneas límite municipales», 30 de julio de 2015. Disponible en http://centrodedescargas.cnig.es/CentroDescargas/

CENTRO NACIONAL DE INFORMACIÓN GEOGRÁFICA. «Centro de descargas - Modelo digital del terreno MDT200», 30 de julio de 2015. Disponible en http:// centrodedescargas.cnig.es/CentroDescargas/

CENTRO NACIONAL DE INFORMACIÓN GEOGRÁFICA. «Centro de descargas Nomenclátor Geográfico de Municipios y entidades de población», 4 de agosto de 2015. Disponible en http://centrodedescargas.cnig.es/CentroDescargas/

CHIQUILLO, N.Y. (2013): Propuesta de uso de los sistemas de información geográfica para la valoración de los recursos naturales y su potencialidad turística: aplicación parque natural Cabo de Gata-Níjar (Andalucía), Trabajo Final de Máster Universitario en Dirección y Planificación del Turismo. Universidad de Málaga.

CONSEJO SUPERIOR GEOGRÁFICO. «Infraestructura de Datos Espaciales de España - INSPIRE», 4 de agosto de 2015. Disponible en http://www.idee.es/europeo-inspire

DYE, A.S., SHAW, S-L (2007): «A GIS-based spatial decision support system for tourists of the Great Smoky Mountains National Park». Journal of Retailing and Consumer Services, vol. 14 (4), pp. 269-278.

EARTH REMOTE SENSING DATA ANALYSIS CENTER. «ASTER Global Digital Elevation Model (GDEM)», 27 de agosto de 2015. Disponible en http://gdem.ersdac. jspacesystems.or.jp/

ESPAÑA. «Ley 7/1985, de 2 de abril, reguladora de las Bases del Régimen Local, en su Título II, artículo 11». Boletín Oficial del Estado, 3 de abril de 1985, número 80, pp. 8945-8964.

ESPAÑA. «Real Decreto 1071/2007, de 27 de julio, reguladora del sistema geodésico de referencia oficial». Boletín Oficial del Estado, 29 de agosto de 2007, número 207, pp. 35986-35989.

FRIEDMAN, R. (2003): «Marketing estratégico y participativo de ciudades». Obregón. Primera reunión de la red de marketing y desarrollo urbano, noviembre.

GARCÍA CRUZ, J.I. (2015): «El análisis del impacto territorial del tercer boom turístico en Canarias (España) a través de la aplicación de un sistema de información geográfica (SIG)», Cuadernos de Turismo, $\mathrm{n}^{\circ} 36$, pp. 219-245.

GARCÍA-ESCUDERO, P. (2015): «La importancia de una marca geográfica. Experiencia española». Conferencia de Patricia García-Escudero, Directora General de la Oficina Española de Patentes y Marcas, en III Seminario regional sobre marcas y diseños industriales como factores de innovación y activos empresariales, Cartagena de Indias. Disponible en http://www.oepm.es/comun/documentos_relacionados/ Ponencias/93_05_26al29oct2015_III_SeminarioRegionalConstruyendoMarcaPais_ Colombia.pdf

GEORGE, P. (Dir.) (2007): Diccionario Akal de Geografía. Akal / Básica de Bolsillo. Ediciones Akal, Madrid.

GILL N., BHARATH B.D. (2013): «Identification of optimum path for tourist places using GIS based network analysis: a case study of New Delhi». International Journal of Advancement in Remote Sensing, GIS and Geography (IJARSGG), vol. 1 (2), pp. 34-38. 
GONZÁLEZ OÑATE, C., MARTÍNEZ BUENO, S. (2013): «La marca territorio como elemento de comunicación: factor estratégico del desarrollo turístico en Cuenca». Pensar la Publicidad, Vol. 7, nº 1, pp. 113-134. http://dx.doi.org/10.5209/rev_PEPU.2013. v7.n1.42439

INSTITUTO GEOGRÁFICO NACIONAL. «Geodesia. Sistemas Geodésicos de Referencia», 25 agosto 2015. Disponible en http://www.ign.es/ign/layoutIn/actividadesGeodesiaStmagd.do

INSTITUTO NACIONAL DE ESTADÍSTICA. «Relación de municipios y códigos por provincias a 01-01-2010», 13 de agosto de 2015. Disponible en http:/www.ine.es/ daco/daco42/codmun/codmun10/10codmunmapa.htm

JAPAN SPACE SYSTEMS. «ASTER Global Digital Elevation Model (GDEM)», 27 de agosto de 2015. Disponible en http://www.jspacesystems.or.jp/ersdac/GDEM/E/4.html

JENNINGS, K. (2012): Un mapa en la cabeza. Editorial Ariel, Barcelona.

JOVANOVIC, V., NJEGUS, A (2013): «The Use of GIS in Tourism Supply and WEB Portal Development». International Journal of Information Technology (IREIT), 1(5), pp. 292-299.

LOBO MONTERO, P. (1999): «Sistema de información Geográfica para el análisis del turismo (SIGTUR). Aspectos metodológicos». Estudios Turísticos, n ${ }^{\circ}$ 142, pp. 57-71.

LUACES, M.R., PEDREIRA, O., PLACES, A.S., SECO, D. (2008): «Los sistemas de información geográfica en turismo». ROTUR/Revista de Ocio y Turismo, $\mathrm{n}^{\circ} 1$, pp. 117-134.

MAGRAMA. «Descargas del Ministerio de Agricultura, Alimentación y Medio Ambiente», 2 de agosto de 2015. Disponible en http://servicios2.magrama.es/sia/visualizacion/descargas/capas.jsp

MAGRAMA (2014): «Memoria de la red de parques nacionales», 31 julio 2015. Ministerio de Agricultura, Alimentación y Medio Ambiente. Organismo Autónomo de Parques Nacionales. Disponible en http://www.magrama.gob.es/es/red-parques-nacionales/lared/gestion/memoria2013_tcm7-361573.pdf

MÍNGUEZ GARCÍA, M.C, de la CALLE VAQUERO, M., GARCÍA HERNÁNDEZ, M. (2008): «Nuevas lecturas territoriales de las actividades turístico-deportivas: huella digital y SIG», en Análisis espacial y representación geográfica: innovación y aplicación. Universidad de Zaragoza-AGE, pp. 759-769.

MINISTERIO DE FOMENTO (2015): «Resumen descriptivo del Nomenclátor de Municipios y Entidades de Población», 10 junio 2015. Dirección General del Instituto Geográfico Nacional Disponible en http://centrodedescargas.cnig.es/CentroDescargas/ equipamiento/BD_Municipios-Entidades.zip

MUÑOZ MAZÓN, A., FUENTES MORALEDA, L. (2013): «La cooperación público privada en el ámbito de la promoción de los destinos. El análisis de redes sociales como propuesta metodológica». Cuadernos de Turismo, nº 31, pp. 199-223.

ORSI - OBSERVATORIO REGIONAL DE LA SOCIEDAD DE LA INFORMACIÓN DE CASTILLA Y LEÓN (2010): Los Sistemas de Información Geográfica en el ámbito de las Entidades Locales. Junta de Castilla y León. Disponible en http://www.rmd.jcyl.es/web/ jcyl/MunicipiosDigitales/es/Plantilla100Detalle/1274785511218/_/1281175732944/ Redaccion 
POZO, G. (2011):, «La batalla por el nacimiento del Guadalquivir», Diario de Sevilla, 15 de mayo de 2011 Disponible en http://www.diariodesevilla.es/article/andalucia/975633/la/batalla/por/nacimiento/guadalquivir.html

REAL ACADEMIA DE LA LENGUA. «Diccionario de la lengua española», 10 de agosto de 2015. Disponible en http://www.rae.es

RENGIFO GALLEGO, J.I., SÁNCHEZ MARTÍN, J.M., SÁNCHEZ RIVERO, M. (2013): «Análisis del desarrollo del turismo rural en la provincia de Cáceres en los inicios del siglo XXI». Pasos, Revista de Turismo y Patrimonio Cultural, vol. 11, $\mathrm{n}^{\circ}$ 4, pp. 615-630.

SÁNCHEZ RIVERO, M. (2008): «Análisis espacial de datos y turismo: nuevas técnicas para el análisis turístico. Una aplicación al caso extremeño». Revista de Estudios Empresariales, $\mathrm{n}^{\circ}$ 2, pp. 48-66.

SÁNCHEZ MARTÍN, J.M., LECO BERROCAL, F., GURRÍA GASCÓN, J.L., PÉREZ MARTÍN, M.N. (2000): «La planificación del turismo rural sostenible en Extremadura mediante SIG», en Tecnologías geográficas para el desarrollo sostenible. Departamento de Geografía, Universidad de Alcalá, pp. 544-573.

SOBRAL GARCÍA, S. (2008): «La caracterización de un espacio turístico a través de un SIG». En: Tecnologías de la Información Geográfica para el Desarrollo Territorial. Servicio de Publicaciones y Difusión Científica de la ULPGC. Las Palmas de Gran Canaria. pp. 424-435.

TURESPAÑA. (2014): Plan estratégico de Marketing 2014-2015. Instituto de Turismo de España. Disponible en http://www.tourspain.es/es-es/Marketing/PEM/Paginas/Default. aspx

VISITNORWAY. «Cabo Norte - el extremo norte de Europa», 31 de julio de 2015. Disponible en http://www.visitnorway.com/es/donde-ir/norte-de-noruega/the-north-capearea/cabo-norte---el-extremo-norte-de-europa/ 